\title{
Doenças exantemáticas e primeira epidemia de dengue ocorrida em Manaus, Amazonas, no período de 1998-1999
}

\author{
Exanthematous diseases and the first epidemic of dengue to occur \\ in Manaus, Amazonas State, Brazil, during 1998-1999
}

\author{
Regina Maria Pinto De Figueiredo ${ }^{1}$, Bedsy Dutary Thatcher ${ }^{1}$, Mário Lira de Lima ${ }^{1}$, \\ Tânia Carvalho Almeida ${ }^{1}$, Wilson Duarte Alecrim ${ }^{1}$ e Marcus Vinitius de Farias Guerra ${ }^{1}$
}

\begin{abstract}
RESUM0
Em 1998, a Fundação de Medicina Tropical/Instituto de Medicina Tropical do Amazonas implementou o sistema de vigilância para síndromes febris agudas indiferenciadas, com o propósito de manter vigilância ativa e passiva na Amazônia Ocidental, Brasil, permitindo identificar e diagnosticar os agentes etiológicos causadores de febres agudas. 0 diagnóstico foi realizado através de estudos sorológicos para a detecção de anticorpos IgM, utilizando-se técnicas de ELISA (Enzyme-linked-immunosorbent assay) e kits ELISA comerciais. Foram analisadas 8.557 amostras de soros de pacientes com suspeita clínica de dengue, $40 \%$ dos soros foram ELSA positivos para 0 vírus da dengue e $26 \%$ dos soros foram ELISA positivos para outras doenças exantemáticas virais como rubéola, sarampo, parvovírus, oropouche e mayaro.
\end{abstract}

Palavras-chaves: Dengue. Epidemia. Doenças exantemáticas. Diagnóstico.

\begin{abstract}
In 1998, the FMT/IMT-AM foundation implemented the surveillance system to diagnose acute undifferentiated febrile syndromes, with the objective of active and passive surveillance in Brazilian western Amazonian rainforest to identify and diagnose the etiologic agents of acute fever. The diagnoses were performed using serological tests to detect IgM antibodies by ELSA (Enzyme-linked-immunosorbent assay) CDC/OPAS or using commercial kits. A total of 8,557 serum samples obtained from patients with clinical su spicion of dengue virus were analyzed. ELISA positive reaction to dengue virus was presented by $40 \%$ of the serum samples and $26 \%$ of the serum samples had positive ELISA reactions to other exanthematous viral diseases, such as rubella, measles, parvovirus, Oropouche virus and Mayaro virus.
\end{abstract}

Key-words: Dengue. Epidemic. Diseases. Exanthematous. Diagnosis.

0 dengue clássico e a febre hemorrágica do dengue são as arboviroses mais difundidas no mundo, constituindo causas importantes de morbidade e mortalidade, resultando em epidemias de impacto em saúde pública. A transmissão do vírus dengue aumenta proporcionalmente em relação à expansão do vetor principal, Aedes aegypti, nos grandes centros urbanos do Novo Mundo2. 0 estabelecimento dos quatro sorotipos nas Américas, levou ao ressurgimento da febre clássica e da febre hemorrágica do dengue (DHF) nessa região ${ }^{8}$.

No Brasil, o primeiro registro, documentado clínica e laboratorialmente, ocorreu em 1982, em Boa Vista (Estado de
Roraima), causado pelos sorotipos 1 e 4, quando cerca de 11.000 pessoas foram infectadas ${ }^{79}$. Em 1986, foram registradas várias epidemias de dengue nos Estados do Rio de Janeiro, São Paulo, Minas Gerais, Alagoas e Ceará ${ }^{10}$. E em todos os casos, 0 sorotipo dengue 1 foi a causa. 0 sorotipo dengue 2 foi isolado pela primeira vez na cidade de Belém (Estado do Pará) de um paciente procedente de Luanda, Angola, em 1989 e, no Rio de Janeiro, de pacientes autóctones em $1990^{\circ}$. Posteriormente, foi identificado também em Tocantins, Alagoas e Ceará ${ }^{10} 12$.

Em 1995, pela primeira vez, casos autóctones de dengue foram reportados em território paraense, nos municípios de

1. Fundação de Medicina Tropical do Instituto de Medicina Tropical do Amazonas, Manaus, AM.

Endereço para correspondência: Dra. Regina Maria Pinto de Figueiredo. Lab. de Arbovirologia. Av. Pedro Teixeira s/nº, Dom Pedro I, $69040-000$ Manaus, AM. Tel: 92 238-3192; 92 238-1711 ramal 288

Fax: 92 238-3762

e-mail: regina68@ig.com.br

Recebido para publicação em 25/8/2003

Aceito em 17/9/2004 
Redenção e Rondon ( Estado do Pará) . No ano seguinte, surtos da infeção foram reconhecidos novamente em redenção e, pela primeira vez na Cidade de Belém, em todos os episódios o agente responsável foi 0 dengue $1^{5}$. A intensa circulação viral (DEN1 e DEN 2) nos anos subseqüentes gerou epidemias que foram se expandindo para todas as regiões brasileiras, com exceção de Santa Catarina e Rio Grande do Sul, que apresentaram somente casos importados. Dos estados da região norte, além de Roraima, notificaram surtos Acre, Amapá, Pará, Rondônia, Tocantins e Amazonas".

Na Cidade de Manaus, o A aegypti foi encontrado em novembro de 1996 e, através do Programa de Vígilância para Síndromes Febris Indiferenciadas implantado pela Fundação de Medicina Tropical/ Instituto de Medicina Tropical do Amazonas (FMT/IMT-AM), foi possível detectar em março de 1998 o início de uma variedade de doenças febris agudas com e sem manifestações hemorrágicas que poderiam ser diagnosticadas como dengue ou não, por se tratar de uma doença cujos sintomas são facilmente confundíveis com os de outras doenças febris exantemáticas.

0 presente trabalho teve como objetivos descrever a epidemia de dengue ocorrida em Manaus, no período de março de 1998 a dezembro de 1999, identificar e diagnosticar os agentes etiológicos causadores de síndromes febris exantemáticas nos soros negativos para 0 dengue.

\section{MATERIAL E MÉTODOS}

As amostras de sangue foram obtidas de pacientes atendidos na FMT/IMT-AM e em outras unidades de saúde da cidade de Manaus e de outras cidades do Estado do Amazonas, com histórico de febre sem evidências de sintomas respiratórios das vias aéreas superiores e com um período de 5 dias ou mais do início dos sintomas. Os soros foram obtidos por centrifugação a $1500 \mathrm{rpm}$, na temperatura de $5^{\circ} \mathrm{C}$, durante 15 minutos e armazenados a $-20^{\circ} \mathrm{C}$. 0 teste MAC-ELISA foi 0 procedimento sorologico escolhido para detectar a presença de anticorpos IgM para dengue, mayaro e oropouche, de acordo com a técnica descrita por Kuno et $\mathrm{al}^{6}$. 0 diagnóstico para rubéola, sarampo e parvovirose foi realizado através de kits ELSA comerciais (Rubenostika IgM II , Enzygnost IgM, Parvovirus B19 IgM EIA). As amostras com sorologia negativa foram testadas, identificando outras doenças exantemáticas com quadro similar a dengue como rubéola, sarampo, parvovírus, mayaro e oropouche.

\section{RESULTAD0S}

No período de março de 1998 a dezembro de 1999, foram testadas 8.557 amostras, das quais $40 \%$ foram positivas para dengue. Pacientes do sexo feminino representaram $53,61 \%$ dos casos e masculino 46,38\% (Figura 1). A análise dessa epidemia em Manaus, por faixa etária, indica que o maior número de casos ocorreu em pacientes adultos entre 25-40 e 41-65 anos (Figura 2), representando $64 \%$ dos casos confirmados sorologicamente. Febre, cefaléia e mialgias foram os sintomas mais freqüentes.

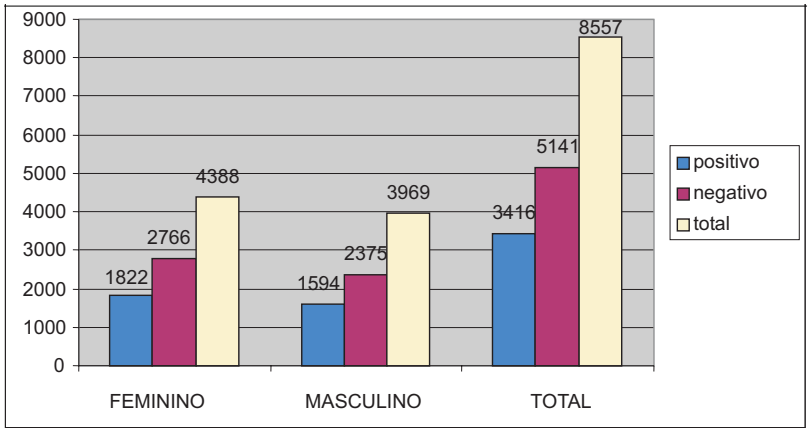

Figura 1 - Pacientes positivos e negativos por sexo 1998-1999.

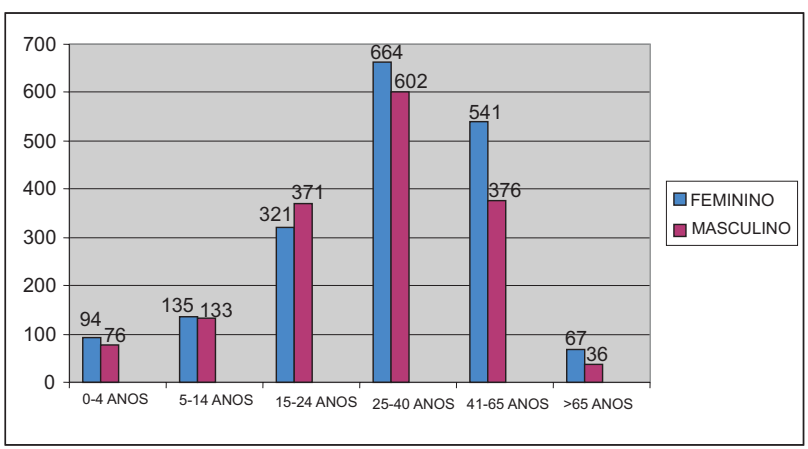

Figura 2 - Pacientes positivos e negativos por faixa etária 1998-1999.

Soros de 81 pacientes suspeitos de dengue, provenientes de 19 diferentes municípios do Estado do Amazonas foram encaminhados à FMT-AM, pelos respectivos Centros de Saúde de cada comunidade. Os soros provenientes de pacientes dos municípios de Autazes, Careiro, Coari, Iranduba, Manacapuru e Tefé, foram soropositivos para dengue (Figura 3).

A época de maior precipitação pluviométrica em Manaus, coincidiu com o pico da epidemia.

Outro parâmetro analisado foi 0 endereço da residência, observando-se que os bairros da zona Sul da cidade, próximos ao Rio Negro, provável sítio de entrada tanto para 0 vetor quanto para 0 vírus, foram os primeiros e os mais afetados.

A sorologia de amostras negativas para dengue resultou no diagnóstico de 1.107 casos de outras doenças exantemáticas e a descrição dos primeiros casos de parvovírus B19 no Estado do Amazonas ( Figura 4). Em 1999, as amostras de pacientes com febre e exantema foram testadas de acordo com 0 diagnóstico clínico para dengue, rubéola, parvovírus, oropouche e mayaro.

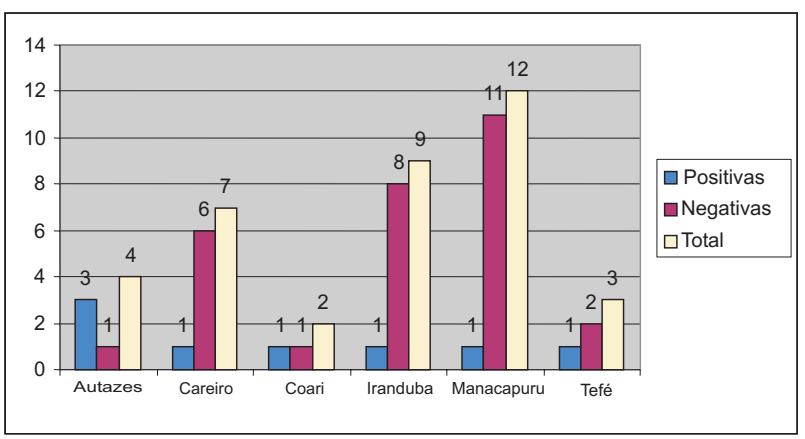

Figura 3 - Total de pacientes positivos e negativos de diferentes municípios do Estado do Amazonas, 1998-1999. 


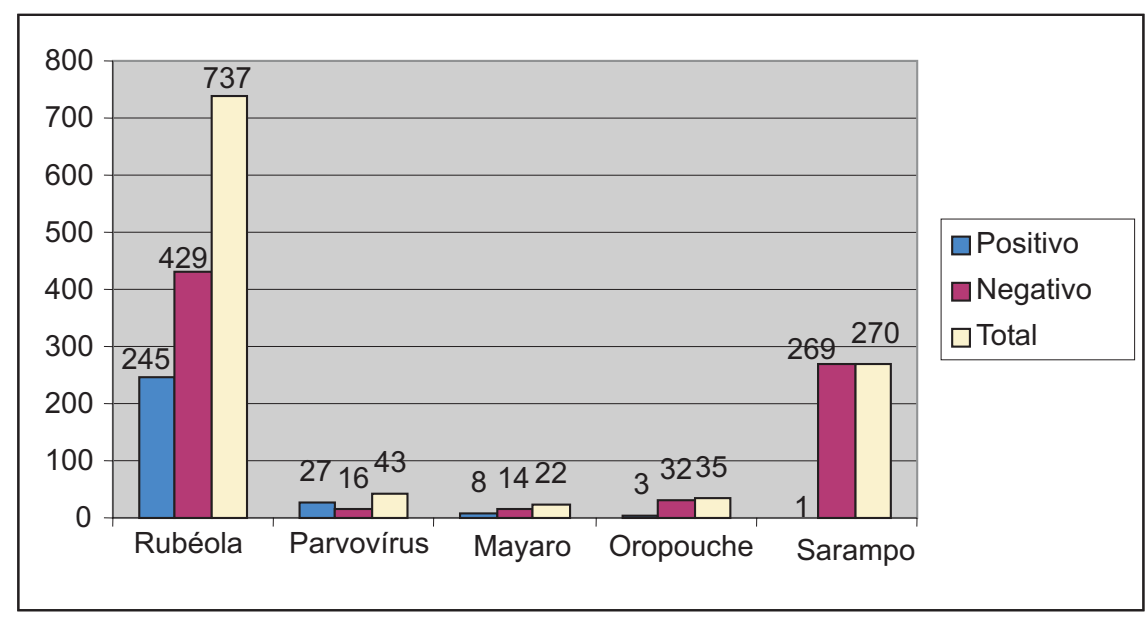

Figura 4 - Diagnóstico sorológico de amostras negativas para dengue, 1998-1999.

\section{DISCUSSÃ0}

Ainfeção com 0 vírus da dengue resulta em uma variedade de sintomas que podem ser confundidos com os de muitas outras doenças exantemáticas. Por esse motivo muitas doenças infecciosas importantes não são diagnosticadas ou mal conduzidas. Alguns dos casos soronegativos registrados durante a epidemia de dengue em Manaus, foram causadas por: vírus mayaro, oropouche, rubéola, sarampo e parvovírus.

Aspectos semelhantes foram observados em amostras coletadas de municípios do Estado do Pará, 0 vírus dengue foi 0 responsável pela maioria das infeções recentes. № entanto, os resultados sorológicos sugerem que outros Flavivirus, tais como 0 da Encefalite São Luís e de Ilhéus (ILH) , circulam na região e podem ser os responsáveis por quadros febris agudos, sem diagnóstico definido ${ }^{1}$.

№ Brasil, a dengue apresenta um padrão sazonal, com maior incidência de casos nos primeiros cinco meses do ano, que correspondem ao período mais quente e úmido, típico de clima tropical ${ }^{3}$. Em Manaus, os casos de dengue reduziram com 0 declínio das chuvas, voltando a aumentar consistentemente com 0 aumento da precipitação.

0 fator de risco mais importante para o dengue é morar ou circular em áreas onde estejam ocorrendo casos, especialmente na vigência de epidemias. № entanto, outros aspectos devem ser considerados, pois podem significar ou representar um risco aumentado de contrair a dengue clássica ou hemorrágica, tais como: faixa etária e sex $0^{5}$.

A análise da epidemia de dengue, por faixa etária, indica que todos os grupos foram afetados sendo que o maior número de casos ocorreu entre as faixas etárias de 25 e 65 anos. 0 mesmo resultado foi observado, no Estado do Pará em 1999, onde os grupos mais vulneráveis foram aqueles com maior atividade produtiva ${ }^{1}$.

Na Ásia, Cuba e Venezuela, o dengue hemorrágico tem ocorrido mais em indivíduos abaixo de 15 anos de idade, diferente do que foi observado nas epidemias ocorridas no Rio de Janeiro e Ceará11 1213 .
Nos 57 bairros da cidade de Manaus ocorreram casos de dengue, no entanto, existe maior concentração no centro da cidade onde se encontra, com frequiência, o Aedes aegypti e a maior população humana ativa durante 0 dia. A doença disseminou-se, provavelmente, de pacientes que contraíram 0 vírus em seus locais de trabalho e transmitiram para outras pessoas em suas moradias, localizadas em outros bairros da cidade.

Este fato pode explicar porque os primeiros casos de dengue foram predominantemente masculinos e, à medida que a epidemia progredia, os casos femininos foram surgindo, não existindo mais diferença estatisticamente significativa entre os sexos.

Através do diagnóstico precoce dos agentes etiológicos das enfermidades que cursam com febre, será possível definir o perfil das doenças no Estado do Amazonas, possibilitando desenvolver ações adequadas de controle e prevenção, principalmente daquelas onde o bloqueio é possível.

\section{AGRADECIMENTOS}

Aos Drs. Vera Margarete Scarpassa (INPA, Manaus, AM), Jorge Luís Lopez- Lozano (FMTAM) e Luís Carlos de Lima Ferreira (FMTAM) pelas valiosas sugestões e correção do manuscrito.

\section{REFERÊNCIAS BIBLIOGRÁFICAS}

1. Araújo TP, Rodrigues SG, A. Costa MIW, Vasconcelos PFC, Travassos da Rosa APA. Diagnóstico sorológico de infeções por dengue e febre amarela em casos suspeitos no Estado do Pará, Brasil, 1999. Revista da Sociedade Brasileira de Medicina Tropical 36:579-584,2002.

2. Clark G C. Dengue and Dengue Hemorrhagic Fever. J Fl Mosq Cont Assoc. 63: 48-53, 1992.

3. Fundação Nacional de Saúde. Boletim Epidemiológico. Ministério da Saúde. Brasília, 1999.

4. Fundação Nacional de Saúde. Boletim Epidemiológico. Ministério da Saúde. Brasília, 2000.

5. Instituto Evandro Chagas. Doenças Infecciosas e parasitárias: Enfoque Amazônico. CEJUP/ Universidade do Estado do Pará: Belém, p. 886, 1997. 
6. Kuno G, Gomez I, Gubler, DJ. Detecting artificial antidengue IgM immune complexes using an enzyme-linked immunosorbent assay. American Journal of Tropical Medicine and Hygiene 36: 153 - 159, 1987.

7. Osanai, CH, Travassos da Rosa APA, Tang AT, Amaral RS, Passos AC, Tauil PL. Surto de dengue em Boa Vista, Roraima. Revista do Instituto de Medicina Tropical de São Paulo 25: 53-54, 1983.

8. Pinheiro FP. Dengue hemorrhagic fever (DHF) and dengue shock syndrome (DSS) in the Americas. Proceedings of the first International Seminar on Dengue, Rio de Janeiro, Brazil, 1996.

9. Rosa APAT, Rocha JM, Silva OV, Lins ZC. Surto de dengue em Boa Vista, Território de Roraima, Brasil. Boletim Epidemiológico. Rio de Janeiro, 14: 93-100, 1982
10. Rosa APAT, Vasconcelos PFC, Pinheiro FP, Rosa JFST, Rodrigues SG. Dengue. In: Leão RNQ(Coord) , Doenças Infecciosas e Parasitárias: Enfoque Amazônico. CEJUP/Universidade do Estado do Pará: Belém, p. 227- 248, 1997.

11. Vasconcelos PFC. A large epidemic of dengue fever with dengue hemorrhagic cases in Ceará State, Brazil, 1994. Revista do Instituto de Medicina Tropical de São Paulo 37: 253-255,1995.

12. Vasconcelos PFC, Rosa APAT, Degallier N, Rosa JFST, Pinheiro FP. Clinical and ecoepidemiological situation of human arboviruses in Brasilian Amazônia. Ciência e Cultura 44: 117-124, 1992.

13. Zagne SMO. Dengue hemorrhagic fever in the state of Rio de Janeiro, Brazil: a study of 56 confirmed cases. Transactions of the Royal Society of Tropical Medicine and Hygiene 88: 677-679, 1994. 